\title{
Relationship between Spiritual Well-being and Quality of Life among Chronically Ill Individuals
}

\author{
Kanwal Shahbaz ${ }^{1}$, Dr. Kiran Shahbaz ${ }^{2}$
}

\section{ABSTRACT}

The study was aimed to find the relationship between Spiritual Wellbeing and Quality of Life among chronically ill individuals. Likewise, relationship between demographic variables with Quality of Life and Spiritual Wellbeing were also reconnoitered. Non probability purposive sampling technique was used with chronically ill patients of $15 \mathrm{yrs}$ to 80yrs. For measuring spiritual wellbeing Urdu version of "Spiritual Wellness Inventory" (SWI-URDU) (Hanif, 2010) was used. Alternatively, for the measurement of Quality of life WHO Quality of Life Questionnaire (WHO-QOL-BREF) was used. A sample of 200 chronically ill patients were taken from four different hospitals of Rawalpindi and Islamabad. Reliabilities of both the instruments were computed as 0.90 for SWI and 0.74 for WHO-QOL-BREF. Findings show that quality of life and Spiritual wellbeing is positively related among chronically ill individuals. Males found to score high on spiritual wellbeing than females. Individuals with less education are more spiritually inclined as compared to individuals with high education. Quality of life was scored high by individuals with higher education as compared to less education. Married individuals were having better quality of life than unmarried, separated widow and divorced. Patients with middle socio-economic status were having better quality of life than higher and lower. Quality of life was high among individuals with better monthly income than those who have low and middle monthly incomes. Spiritual well being is higher in middle adolescents (15-17) than in late (18-20) adolescents. The current research can be implemented in designing the intervention plans for the betterment of chronically ill patients. It may also help us to develop an insight that each patient with same disease but in different age group and socio-economic status has different needs and plans of treatment and care.

Keywords: Spiritual well being, counseling, chronically ill patients, quality of life, psychological well being, intervention plan, healthy life, lungs cancer, breast cancer, environmental factors.

\footnotetext{
${ }^{1}$ Center for Counseling and Career Advisory C3A, NUST, Islamabad, Pakistan.

${ }^{2}$ Department of Counseling and Rehabilitation, Perfect Health Pvt. Ltd, Islamabad, Pakistan

(c) 2015 I K Shahbaz, K Shahbaz; licensee IJIP. This is an Open Access Research distributed under the terms of the Creative Commons Attribution License (http://creativecommons.org/licenses/by/2.0), which permits unrestricted use, distribution, and reproduction in any Medium, provided the original work is properly cited.
} 
Spiritual wellbeing refers to the feeling of peace and satisfaction originating from the relationship with spiritual aspects of an individual's life (Lancet, 2003).It plays a vital role in psychic adjustment, experiencing, meaning and purpose of life possessing effect on different domains of life (Dunn\& Charles, 1977) enhancing of depriving its quality. Spirituality is achieved by spiritual acts like mediation and prayers. The level to which one is spiritually inclined will describe its spiritual wellbeing(Hall, 1992). Spirituality or Holy Name is an ancient form of prayer that helps to reduce stress and upsurge relaxation and considered significant. Likewise, Quality of Life is another important factor that influences the life of an individual and its various components including physical, psychological, social, and environmental aspects so that they can fit themselves best into environment (Cantrell \& Mary, 2000). There is a great tendency that chronically ill individuals can have enhanced or deprived spiritual wellbeing or Quality of Life which influences recovery of patients. The present study aims to measure the spiritual wellbeing and quality of life among chronically ill individuals.

Spirituality a Latin word, derived from 'spiritus' which means courage, breath, wind, vigor, and life (Hill, Pargament, Hood, McCullough, Swyers, Larson \& Zinnbauer, 2000), described as an internal, personal, informal and involving the heart (Cook, 2000) while Legere (1984) states that it concerns as the internal experience. Spirituality is the natural connection of human with the wonders and energy of nature, universe and all existence; and the instinct to discover and comprehend its meaning (Jenkins, 2000), referring to inner sight permitting a person to find meaning of live. Therefore, certain Spiritual practices, such as meditation, prayer and contemplation, are aimed to develop and modify an individual's inner life; these practices leads to an experience of connectedness with a larger reality or with divine kingdom. It can take in belief in irrelevant realities or experiences of the inspirational nature of the world (Azeemi, 2005).

'Spirituality' as an umbrella and 'religion' refers to what is under that umbrella. Religion can be part of one's spirituality (Miller, 1997; Azeemi, 2005)without Spiritual vision; belief is nothing but an assumption and is not a synonym for religion (David, 2009).Spirituality and religious belief is not identical and they may or may not co-exist (Kevin, 2000). Spirituality is fundamental feeling of being connected with one's complete self, others and the complete universe. It is inclusive, universally applicable and approval of diverse expression emphasizing interconnectedness of self being (Denton, 1999). Whereas Elizabeth (1999) states Religionas dogmatic (inflexible), exclusive (limited), disruptive and narrow.

Wellbeing is an absolute state of physical, mental and social security and comfort. Whereas spiritual well-being is multidimensional condition of unfolding the survival of positive health in an individual along with quality of life and sense of connectedness with higher power (World Health Organization, 2005).Conceptual confab of spiritual wellbeing connects it to leisure which is a mental activity and spiritual approach, a state of the soul, a receptive and thoughtful attitude of mind (Heintzman, 2002).Motivation is an important factor in the development of spiritual 
wellbeing. It can be encouraged by both intentional activity and spontaneous events (Chandler, 2000).

The World health Organization defines Quality of life as the individual's perceptions of their position in life in context of culture and civilization. And value system in which they live in relation to their goals, opportunity, principles, standards and their concerns (WHO-QOL-Group, 2005).Robert (2010) an ecological economist says Quality of Life (QOL) is a precise or understood strategy area; satisfactory definition and measurement is mysterious. Individual's perception and sensitivity is being influenced by the spirituality and culture that an individual live in.

\section{METHOD}

\section{Hypothesis}

1. Spiritual Wellbeing and Quality of Life will be positively correlated among chronically ill individuals.

2. Spiritual Wellbeing will be higher in middle adolescence as compared to late adolescent among chronically ill individuals

3. Males will score high on Spiritual Wellbeing than females among chronically ill individuals.

4. Chronically ill individuals with low education will score high on Spiritual Wellbeing than higher education individuals.

5. Chronically ill individuals with high education will score high on Quality of Life than individuals with less education.

6. Married chronically ill individuals will score high on Quality of Life than unmarried, separated, widowed and divorced.

7. Chronically ill individuals with middle socio-economic status will score high on Quality of Life than higher and lower.

8. Quality of Life will be higher among chronically ill individuals with high monthly incomes than individuals with lower or middle income.

\section{Sample}

Non probability Purposive sampling technique with 15yrs to 80yrs patients from four different hospitals of Islamabad and Rawalpindi were taken. Patients with blood cancer, lung cancer, breast cancer, and cancer in genitals, tumors in brain, renal failure, Asthma, Diabetes, HIV++, tuberculosis and chronic obtrusive pulmonary disease (COPD) were the participants.

\section{Instruments}

Following two instruments were used for the conduction of this study. 


\section{Relationship between Spiritual Well-being and Quality of Life among Chronically III Individuals}

- $\quad$ Spiritual Wellness Inventory (SWI)

- $\quad$ WHO Quality of Life Questionnaire (WHO-QOL-BREF)

\section{Spiritual Wellness Inventory (SWI)}

Spiritual Wellness Inventory was developed by Ingersoll (1998). It was translated in Urdu by Gohar (2005). It comprises of 13 subscales and 65 items. Each subscale of SWI consists of five items. Odd items are negatively scored whereas even items are positively scored. It is based on Likert-type 4-point rating scale. The response categories include strongly agree $=4$, agree $=3$, disagree $=2$, and strongly disagree $=1$. There is no cut off scores in the scale therefore high scores indicate high spiritual wellbeing and vice versa. The subscales included Knowledge of Divinity (items 1, 14, 27, 40, 53), Meaning (items 1, 14, 27, 40, 54), Connectedness (items 2, 15, 28, 41, 55), Present-Centeredness (items 3, 16, 29, 42, 56), Mystery (items 4, 17, 30, 43, 57), Ritual (items 5, 18, 31, 44, 58), Hope (items 6, 19, 32, 45, 59), Forgiveness (items 7, 20, 33, 46, 60), Knowledge/Meaning (items 8, 21, 34, 47, 61), Conscientiousness (items 9, 22, 35, 48, 62), Spiritual Freedom (items 10, 23, 36, 49, 63), Altruism (items 11, 24, 37, 50, 64), and Concept of Hereafter (items 12, 25, 38, 51, 55).By factor analysis in Pakistan on Pakistani data it was converted to uni-factor scale having 60 items (Hanif, 2010), measuring the whole construct of Spiritual Wellbeing.

\section{WHO Quality of Life Questionnaire (WHO-QOL-BREF)}

World Health Organization Quality of Life Questionnaire was developed by Power (2003). It was translated in Urdu by Khan, Akhtar, Ayub, Alam, and Laghari (2003). The questionnaire consists of 26 items and comprise of four subscales. The questionnaire is a 5-point ranting scale. Score ranges from 1 (strongly disagree) to 5 (strongly agree). There is no cut off scores in the scale therefore high scores indicate high quality of life and vice versa. Physical Functioning is measured by item numbers (3, 4, 10, 15, 16, 17, and 25). Psychological Functioning is measured by item numbers $(5,6,7,11,18$, and 26$)$. Social Dimension is measured by item numbers (19, 20, and 21). Environment is measured by item numbers (8, 9, 12, 13, 14, 22, 23, and 24). Perception of Quality of life and health is measured by item numbers (1 and 2).

\section{Pre- Testing}

Pre-testing was done on 15 chronically ill individuals. It was found that no problems were found in the understanding of questionnaire in the given sample of chronically ill patients. It gave a path to move to next step of pilot testing.

\section{Pilot study}

Pilot study was done with a sample of 80 chronically ill patients. During pilot testing, item total correlation of item numbers 6, 22, 26 and 30 was relatively low and therefore, they were excluded from the main study. SWI was used with total of 56 items. No item was excluded from 
WHO-QOL-BREF. This technique stood effective for determining relationship between variables.

\section{Procedure}

This study was aimed to explore the relationship between spiritual wellbeing and quality of life among chronically ill patients. For this purpose chronically ill individuals were selected from hospitals of Rawalpindi and Islamabad. We used two questionnaires that is Spiritual Wellness Inventory (SWI- Urdu) and WHO Quality of Life Questionnaire (WHO-QOL-BREF).

Main study was done with SWI- URDU consisting of 56 items. Patients were briefed prior to the administration of questionnaires. Likewise, confidentiality of the information was assured. Data was collected and analyzed through SPSS 19.0, questionnaires with missing values were excluded

\section{RESULTS}

Correlation analysis was carried to identify the relationship between all the variables and its subscales, while t-test was applied to see the mean differences between the variables. ANOVA used to find within group differences among spiritual wellbeing and Quality of life. Post hoc test was applied to check the interaction effect in the population. Cohen's $d$ values were calculated to check the effect size of the population as an effect size is a measure of the strength of the relationship between two variables in a statistical population, And for reliability of the scales alpha coefficient was also computed. The frequencies were calculated in order to know about the distribution of sample in data.

Table 1 Mean standard Deviation and Alpha Reliability for all variables $(N=200)$

\begin{tabular}{lllll}
\hline & Mean & SD & No of items & $\alpha$ \\
\hline SWB Scale & 159.47 & 21.79 & 56 & .90 \\
QOL Scale & 110.37 & 15.34 & 26 & .74 \\
\hline
\end{tabular}

SWB = spiritual wellbeing, $Q O L=$ Quality of life

Table 1 shows mean SD and alpha reliability for spiritual wellbeing (SWB) and Quality of life (QOL) scale. The reliability analysis shows that alpha coefficient for the total scale of spiritual wellbeing is .90, which is reasonably high. The mean SD and Alpha reliability for Quality of life (QOL) scale was also measured which shows that alpha coefficient for the total scale is .74, which is satisfactory and appropriate for the measurement of quality of life of chronically ill patients. 
Relationship between Spiritual Well-being and Quality of Life among Chronically III Individuals

Table 2 Mean, Standard Deviations, Alpha Reliability, and Correlation for Quality of Life and its subscales $(N=200)$

\begin{tabular}{|c|c|c|c|c|c|c|c|c|c|c|}
\hline \multicolumn{2}{|l|}{ Variables } & Mean & $S D$ & $\alpha$ & 1 & 2 & 3 & 4 & 5 & 6 \\
\hline \multirow[t]{6}{*}{ QOL } & & 110.37 & 15.34 & .76 & - & $.80^{* * *}$ & $.73^{* *}$ & $.79^{* *}$ & $.82^{* *}$ & $.42^{* *}$ \\
\hline & . Phy.F & 29.66 & 7.15 & .76 & & - & $.37^{* *}$ & $.47^{* *}$ & $.48^{* *}$ & $.19^{* *}$ \\
\hline & . Psy.F & 24.91 & 3.51 & .65 & & & - & $.66^{* *}$ & $.60^{* *}$ & $.24^{* *}$ \\
\hline & . So.F & 13.44 & 1.84 & .75 & & & & - & $.71^{* *}$ & $.28^{* *}$ \\
\hline & En.F & 34.51 & 5.23 & .67 & & & & & - & $.18^{* *}$ \\
\hline & - PofQOL & 7.86 & 2.79 & .62 & & & & & & - \\
\hline
\end{tabular}

${ }^{* *} p<.01 \mathrm{QOL}=$ Quality of life, Phy.F = physical functioning, Psy.F= Psychological functioning, So. F= Social functioning, En. F= environmental functioning, PofQOL= Perception of Quality of life.

Table 2 shows the Mean, SD, Alpha Reliability and Pearson Correlation for Quality of Life and its subscales. Reliability analysis shows that alpha coefficient for physical functioning is .76 and psychological function is .655 , for social functioning it is .755, for environmental functioning it is .67 and for perception of Quality of Life it's .622. This shows that internal consistency of the scale is satisfactory.

Positive correlation was found in order that how spiritual wellbeing and Quality of life correlate in Pakistani culture. There can be a possibility that both the variable correlate negatively or do not correlate any relationship between them. But positive relation in Pakistani culture occurred in this study shows that both the variables correlate with some relation.

Table 3 Mean, Standard Deviations and t-test for all variables $(N=200)$

\begin{tabular}{|c|c|c|c|c|c|c|c|c|c|}
\hline \multirow[b]{2}{*}{ Variables } & \multicolumn{2}{|c|}{$\begin{array}{l}\text { Male } \\
(n=100)\end{array}$} & \multicolumn{2}{|c|}{$\begin{array}{l}\text { Female } \\
(n=100)\end{array}$} & \multirow[b]{2}{*}{$\begin{array}{l}t \\
(198)\end{array}$} & \multirow[b]{2}{*}{$p$} & \multicolumn{2}{|c|}{$95 \%$ CI } & \multirow[b]{2}{*}{$\begin{array}{l}\text { Cohen's } \\
d\end{array}$} \\
\hline & Mean & $S D$ & Mean & $S D$ & & & $L L$ & $U L$ & \\
\hline SWB & 161.20 & 21.45 & 157.84 & 22.01 & 1.51 & .001 & 1.42 & 10.70 & 0.15 \\
\hline QOL & 110.49 & 14.53 & 110.25 & 16.15 & 0.10 & .625 & 4.05 & 4.52 & 0.01 \\
\hline
\end{tabular}

SWB=Spiritual Wellbeing, $Q O L=$ Quality of Life

Table 3shows the significant difference for spiritual wellbeing over gender. T-test was applied to check the mean differences among males and females. Mean score values shows that males have high spiritual wellbeing than females with degree of freedom $t=198$. Spiritual wellbeing is found to be significant among males and females among chronically ill patients. 
Relationship between Spiritual Well-being and Quality of Life among Chronically III Individuals

Table 4 Mean, Standard Deviations and $F$ for all variables $(N=200)$

\begin{tabular}{|c|c|c|c|c|c|c|c|c|c|c|c|c|c|c|}
\hline \multirow[b]{2}{*}{$\begin{array}{l}\text { Varia } \\
\text { bles }\end{array}$} & \multicolumn{2}{|c|}{$\begin{array}{l}\text { Primary } \\
(\mathrm{n}=6)\end{array}$} & \multicolumn{2}{|c|}{$\begin{array}{l}\text { Middle } \\
(\mathrm{n}=19)\end{array}$} & \multicolumn{2}{|c|}{$\begin{array}{l}\text { Metric } \\
(\mathrm{n}=31)\end{array}$} & \multicolumn{2}{|c|}{$\begin{array}{l}\text { FA/F.Sc } \\
(n=74)\end{array}$} & \multicolumn{2}{|c|}{$\begin{array}{l}\text { Bachelor } \\
(\mathrm{n}=62)\end{array}$} & \multicolumn{2}{|c|}{$\begin{array}{l}\text { Masters } \\
(\mathrm{n}=8)\end{array}$} & \multirow[b]{2}{*}{$F$} & \multirow[b]{2}{*}{$P$} \\
\hline & $\begin{array}{l}\text { Mea } \\
n\end{array}$ & $S D$ & $\begin{array}{l}\text { Mea } \\
n\end{array}$ & $S D$ & $\begin{array}{l}\text { Mea } \\
n\end{array}$ & $S D$ & $\begin{array}{l}\text { Mea } \\
n\end{array}$ & $S D$ & $\begin{array}{l}\text { Mea } \\
n\end{array}$ & $S D$ & $\begin{array}{l}\text { Mea } \\
n\end{array}$ & $S D$ & & \\
\hline \multirow[t]{3}{*}{ SWB } & 17 & 17 & 17 & 5. & 15 & 21 & 15 & 22 & 15 & 21 & 16 & 18 & 4. & .0 \\
\hline & 7.0 & .2 & 5.8 & 60 & 9.1 & .3 & 3.9 & .9 & 8.2 & .2 & 5.3 & .7 & 84 & 00 \\
\hline & 0 & 5 & 9 & & 3 & 8 & 7 & 0 & 9 & 4 & 8 & 4 & & \\
\hline \multirow[t]{3}{*}{ QOL } & 10 & 10 & 11 & 10 & 11 & 16 & 10 & 16 & 11 & 15 & 11 & 9. & 2. & .0 \\
\hline & 7.0 & .0 & 0.4 & .5 & 0.7 & .1 & 9.5 & .6 & 1.0 & .8 & 4.1 & 38 & 22 & 01 \\
\hline & 0 & 8 & 2 & 7 & 4 & 9 & 3 & 2 & 2 & 8 & 3 & & & \\
\hline
\end{tabular}

$S W B=$ spiritual wellbeing, $Q O L=$ Quality of life

Table 4 shows that Quality of life and Spiritual wellbeing are significant to education among chronically ill patients. One way ANOVA was carried out to see the effect of education on both the variables. Mean scores that is 114.13 shows that Quality of life is higher among people with higher education than individuals with less education.

Table 5 Mean, Standard Deviations and F for all variables $(N=200)$

\begin{tabular}{|c|c|c|c|c|c|c|c|c|c|c|c|c|}
\hline \multirow[b]{2}{*}{$\begin{array}{l}\text { Varia } \\
\text { ble }\end{array}$} & \multicolumn{2}{|c|}{$\begin{array}{l}\text { Married } \\
(\mathrm{n}=93)\end{array}$} & \multicolumn{2}{|c|}{$\begin{array}{l}\text { Unmarried } \\
(\mathrm{n}=81)\end{array}$} & \multicolumn{2}{|c|}{$\begin{array}{l}\text { Widow } \\
(\mathrm{n}=11)\end{array}$} & \multicolumn{2}{|c|}{$\begin{array}{l}\text { Divorced } \\
(n=7)\end{array}$} & \multicolumn{2}{|c|}{$\begin{array}{l}\text { Separated } \\
(\mathrm{n}=8)\end{array}$} & \multirow[b]{2}{*}{$F$} & \multirow[b]{2}{*}{$p$} \\
\hline & Mean & $S D$ & Mean & $S D$ & Mean & $S D$ & $\begin{array}{l}\text { Mea } \\
n\end{array}$ & $S D$ & Mean & $S D$ & & \\
\hline QOL & 111. & 14. & 110. & 14. & 105. & 2.3 & 109 & 11. & 95.2 & 32. & 2.6 & .03 \\
\hline & 27 & 21 & 01 & 77 & 64 & 3 & .7 & 38 & 5 & 89 & 1 & 7 \\
\hline SWB & $\begin{array}{l}163 . \\
32\end{array}$ & $\begin{array}{l}21 . \\
32\end{array}$ & $\begin{array}{l}187 . \\
49\end{array}$ & $\begin{array}{l}22 . \\
38\end{array}$ & $\begin{array}{l}155 . \\
27\end{array}$ & $\begin{array}{l}19 . \\
7\end{array}$ & $\begin{array}{l}150 \\
.5\end{array}$ & $\begin{array}{l}15 \\
2\end{array}$ & $\begin{array}{l}148 . \\
25\end{array}$ & $\begin{array}{l}24 . \\
55\end{array}$ & $\begin{array}{l}1.8 \\
4\end{array}$ & $\begin{array}{l}.12 \\
1\end{array}$ \\
\hline
\end{tabular}

SWB $=$ Spiritual Wellbeing, $Q O L=$ Quality of Life

Table 5 shows quality of life is significant with 0.37 to Marital Status among chronically ill patients. 
Relationship between Spiritual Well-being and Quality of Life among Chronically III Individuals

Table 6 Post hoc test for Marital status with Quality of life $(N=200)$

\begin{tabular}{llllll}
\hline Marital status & & & & \multicolumn{2}{l}{$95 \%$ CI } \\
\cline { 5 - 6 } & $(I-J)$ & $S . E$ & $P$ & $L B$ & $U B$ \\
Quality of life & & & & & \\
Married- unmarried & .25 & 2.29 & .91 & -4.27 & 4.78 \\
Married-widow & 5.63 & 4.81 & .24 & -3.86 & 15.13 \\
Married-divorced & -4.44 & 5.91 & .45 & -16.12 & 7.22 \\
Married- separated & $16.01^{*}$ & 5.56 & .004 & 5.05 & 26.99 \\
\hline un married- married & -.26 & 2.29 & .91 & -4.78 & 4.27 \\
un married-widow & 5.36 & 4.85 & .26 & -4.19 & 14.94 \\
un married-divorced & -4.72 & 5.94 & .43 & -16.43 & 7.03 \\
un married- separated & $15.76^{*}$ & 5.59 & .005 & 4.73 & 26.80 \\
\hline Widow- married & -5.62 & 4.81 & .24 & -15.13 & 3.86 \\
Widow-un married & -5.36 & 4.85 & .26 & -14.94 & 4.19 \\
Widow-divorced & -10.08 & 7.30 & .16 & -24.47 & 4.32 \\
Widow-separated & 10.36 & 7.01 & .14 & -3.45 & 24.22 \\
\hline Divorced- married & 4.45 & 5.91 & .45 & -7.22 & 16.12 \\
Divorced-unmarried & 4.72 & 5.94 & .43 & -7.03 & 16.43 \\
Divorced-widow & 10.08 & 7.30 & .16 & -4.32 & 24.47 \\
Divorced-separated & $20.46^{*}$ & 7.81 & .01 & 5.05 & 35.88 \\
\hline Separated- married & $-16.01^{*}$ & 5.56 & .004 & -26.99 & -5.05 \\
Separated-unmarried & $-15.76^{*}$ & 5.59 & .005 & -26.80 & -4.73 \\
Separated-widow & -10.36 & 7.01 & .14 & -24.22 & 3.45 \\
Separated-divorced & $-20.46^{*}$ & 7.81 & .01 & -35.88 & -5.05 \\
\hline Note: S.E- standard & & & & \\
\hline
\end{tabular}

Note: $S . E=$ standard error; $L B=$ lower bound; $U L=$ upper bound, $* p<0.05$

Table 6shows the post hoc results for the marital status with quality of life. Significant relation is found between married and separated individuals. Significant relation is found between unmarried and separated chronically ill individuals. Quality of life is also found significant in separated and divorced chronically ill individuals with $p<0.05$.

Table 7

Mean, Standard Deviations and F for all variables $(N=200)$

\begin{tabular}{|c|c|c|c|c|c|c|c|c|}
\hline \multirow[b]{2}{*}{ Variable } & \multicolumn{2}{|c|}{$\begin{array}{l}\text { High SES } \\
(n=46)\end{array}$} & \multicolumn{2}{|c|}{$\begin{array}{l}\text { Middle SES } \\
(n=105)\end{array}$} & \multicolumn{2}{|c|}{$\begin{array}{l}\text { Low SES } \\
(n=49)\end{array}$} & \multirow[b]{2}{*}{$F$} & \multirow[b]{2}{*}{$P$} \\
\hline & Mean & $S D$ & Mean & $S D$ & Mean & $S D$ & & \\
\hline QOL & 111.20 & 12.69 & 112.33 & 15.98 & 105.39 & 15.38 & 3.60 & .029 \\
\hline SWB & 160.7 & 22.29 & 160.68 & 21.31 & 156.37 & 22.49 & .667 & .514 \\
\hline
\end{tabular}

$S W B=$ Spiritual Wellbeing, $Q O L=$ Quality of Life 
Quality of life has significant relation with Socio-Economic Status. It means that socio-economic status has significant effects on quality of life and because of it will increase or decrease. Application of one way ANOVA shows that QOL is significant to SES. The mean scores indicate that QOL is higher among individuals with middle socio-economic classthan high and low SES among chronically ill patients. It is also found that spiritual wellbeing in non-significant to socioeconomic status. Lower values of $\mathrm{F}$ on spiritual wellbeing scale shows that it is nonsignificant.

Table 8 Post hoc Test for Socio- economic status with Quality of Life (N=200)

\begin{tabular}{llllll} 
Socio-economic status & & & \multicolumn{3}{c}{$95 \%$ CI } \\
\cline { 5 - 6 } & $(I-J)$ & S. E & $P$ & $L B$ & $U B$ \\
\hline High-middle & $Q O L$ & & & & \\
High-low & -1.13 & 2.67 & .671 & -6.42 & 4.14 \\
\hline Middle- high & 5.80 & 3.10 & .063 & -.32 & 11.94 \\
Middle- low & 1.13 & 2.67 & .671 & -4.14 & 6.42 \\
\hline Low-high & $6.94^{*}$ & 2.62 & .009 & 1.78 & 12.11 \\
Low- middle & -5.80 & 3.10 & .063 & -11.94 & .32 \\
& $-6.94^{*}$ & 2.62 & .009 & -12.11 & -1.78
\end{tabular}

Note: $S . E=$ standard error; $L B=$ lower bound; $U L=$ upper bound, $Q O L=$ quality of life $* p<0.05$

Table 8 shows significant differences on Quality of Life between low, high, and middle socioeconomic statuses. The application of post hoc test and results indicate non-significant mean differences in quality of life with respect to low and middle and high socio-economic statuses with $p>.05$.

Table 9 Mean, Standard Deviations and F for all variables $(N=200)$

\begin{tabular}{|c|c|c|c|c|c|c|c|c|}
\hline \multirow[b]{2}{*}{ Variable } & \multicolumn{2}{|c|}{$\begin{array}{l}\text { Less than } 40000 \\
\text { (Low) }\end{array}$} & \multicolumn{2}{|c|}{$\begin{array}{l}\text { Between41000- } \\
60000 \\
\text { (Moderate) } \\
(n=09)\end{array}$} & \multicolumn{2}{|c|}{$\begin{array}{l}\text { Above } 61000 \\
\text { (High) }\end{array}$} & \multirow[b]{2}{*}{$F$} & \multirow[b]{2}{*}{$P$} \\
\hline & Mean & $S D$ & Mean & $S D$ & Mean & $S D$ & & \\
\hline QOL & 109.31 & 13.67 & 111.22 & 17.03 & 120.46 & 4.12 & 2.20 & .05 \\
\hline SWB & 162.01 & 20.07 & 174.44 & 22.08 & 174.1 & 13.92 & 5.05 & .000 \\
\hline
\end{tabular}

SWB=Spiritual Wellbeing, $Q O L=$ Quality of Life, $S D=$ standard deviation

Table 9describes the effect of monthly income on Quality of life and spiritual well being. By the application of One Way ANOVA we got to know that Monthly income is significant to Quality of life. 
Relationship between Spiritual Well-being and Quality of Life among Chronically III Individuals

Table 10 Mean, Standard Deviations and $F$ for all variables $(N=200)$

\begin{tabular}{|c|c|c|c|c|c|c|c|c|c|c|c|c|}
\hline \multirow[b]{2}{*}{$\begin{array}{l}\text { Variab } \\
\text { le }\end{array}$} & \multicolumn{2}{|c|}{$\begin{array}{l}\text { Middle } \\
\text { Adolescent } \\
15-17 \\
(\mathrm{n}=27) \\
\end{array}$} & \multicolumn{2}{|c|}{$\begin{array}{l}\text { Late } \\
\text { Adolescent } \\
18-20 \\
(n=27)\end{array}$} & \multicolumn{2}{|c|}{ Adulthood } & \multicolumn{2}{|c|}{$\begin{array}{l}\text { Middle } \\
\text { Adulthood } \\
41-60 \\
(\mathrm{n}=31) \\
\end{array}$} & \multicolumn{2}{|c|}{$\begin{array}{l}\text { Late } \\
\text { Adulthood } \\
61-80 \\
(n=20) \\
\end{array}$} & \multirow[b]{2}{*}{$F$} & \multirow[b]{2}{*}{$p$} \\
\hline & Mean & $S D$ & Mean & $S D$ & Mean & $S D$ & Mean & $S D$ & Mean & $S D$ & & \\
\hline \multirow[t]{2}{*}{ SWB } & 168. & 22. & 154. & 21. & 153. & 21. & 159. & 18. & 178. & 13. & 7.7 & .00 \\
\hline & 41 & 67 & 00 & 56 & 44 & 20 & 29 & 43 & 95 & 88 & 4 & 0 \\
\hline QOL & $\begin{array}{l}116 . \\
63\end{array}$ & $\begin{array}{l}18 . \\
62\end{array}$ & $\begin{array}{l}115 . \\
73\end{array}$ & $\begin{array}{l}12 . \\
41\end{array}$ & $\begin{array}{l}109 . \\
73\end{array}$ & $\begin{array}{l}12 . \\
63\end{array}$ & $\begin{array}{l}105 . \\
48\end{array}$ & $\begin{array}{l}22 . \\
33\end{array}$ & $\begin{array}{l}112 . \\
00\end{array}$ & $\begin{array}{l}11 . \\
07\end{array}$ & $\begin{array}{l}1.7 \\
9\end{array}$ & .13 \\
\hline
\end{tabular}

SWB=Spiritual Wellbeing, $Q O L=$ Quality of Life

Table 10 shows that spiritual wellbeing is significant with age. That is with age spiritual well being will be influenced. Application of one way ANOVA and Mean scores shows that spiritual wellbeing is higher among middle adolescents than late adolescents. This table also shows that spiritual wellbeing gradually increases with age. It is found to score highest in late adulthood.

Table 11 Post hoc Test for Age with spiritual wellbeing $(N=200)$

\begin{tabular}{|c|c|c|c|c|c|}
\hline \multirow[t]{2}{*}{ Age } & \multirow[b]{2}{*}{$(I-J)$} & \multirow[b]{2}{*}{ S.E } & \multirow[b]{2}{*}{$P$} & \multicolumn{2}{|c|}{$95 \% C I$} \\
\hline & & & & $L B$ & $U B$ \\
\hline & \multicolumn{5}{|c|}{ Spiritual wellbeing } \\
\hline $15-17-18-20$ & $14.40^{*}$ & 5.56 & .010 & 3.43 & 25.39 \\
\hline $15-17-21-40$ & $13.96^{*}$ & 4.46 & .002 & 5.17 & 22.76 \\
\hline $15-17-41-60$ & 9.11 & 5.38 & .092 & -1.50 & 19.74 \\
\hline $15-17-61-60$ & -10.54 & 6.03 & .082 & -22.44 & 1.36 \\
\hline $18-20-15-17$ & $-14.40^{*}$ & 5.56 & .010 & -25.39 & -3.43 \\
\hline $18-20-21-40$ & -.44 & 4.46 & .921 & -9.24 & 8.36 \\
\hline $18-20-41-60$ & -5.29 & 5.38 & .327 & -15.91 & 5.33 \\
\hline $18-20-61-80$ & $-24.95^{*}$ & 6.03 & .000 & -36.85 & -13.05 \\
\hline $21-40-15-17$ & $-13.96^{*}$ & 4.46 & .002 & -22.76 & -5.17 \\
\hline $21-40-18-20$ & .44 & 4.46 & .921 & -8.36 & 9.24 \\
\hline $21-40-41-60$ & -4.84 & 4.23 & .253 & -13.19 & 3.50 \\
\hline $21-40-61-80$ & $-24.50^{*}$ & 5.03 & .000 & -34.43 & -14.58 \\
\hline 41-60- 15-17 & -9.11 & 5.38 & .092 & -19.74 & 1.50 \\
\hline $41-60-18-20$ & 5.29 & 5.38 & .327 & -5.33 & 15.91 \\
\hline $41-60-21-40$ & 4.84 & 4.23 & .253 & -3.50 & 13.19 \\
\hline $41-60-61-80$ & $-19.66^{*}$ & 5.86 & .001 & -31.23 & -8.09 \\
\hline 61-80-15-17 & 10.54 & 6.03 & .082 & -1.36 & 22.44 \\
\hline $61-80-18-20$ & $24.95^{*}$ & 6.03 & .000 & 13.05 & 36.85 \\
\hline $61-80-21-40$ & $24.50 *$ & 5.03 & .000 & 14.58 & 34.43 \\
\hline $61-80-41-60$ & $19.66^{*}$ & 5.86 & .001 & 8.09 & 31.23 \\
\hline
\end{tabular}

Note: $S . E=$ standard error; $L B=$ lower bound; $U L=$ upper bound, ${ }^{*} p<0.05$ 
Table 11shows the application of post hoc test on age with spiritual well being. It is found that significant relation is present between middle (15-17) and late (18-20) adolescents. Another significant relation is found between middle adolescent (15-17) and late (61-80)adulthood. Spiritual wellbeing is also significant in adulthood (21-40) and late adulthood (61-80). Spiritual wellbeing is also found significant in middle adulthood (41-60) and late (61-80) adulthood. Post hoc depicted the interaction effect among the population with $p<0.05$.

Table 12 Mean, Standard Deviations and $t$ for insight of the disease $(N=200)$

\begin{tabular}{|c|c|c|c|c|c|c|c|c|c|}
\hline \multirow[b]{2}{*}{ Variables } & \multicolumn{2}{|c|}{$\begin{array}{l}\text { Yes } \\
(n=159)\end{array}$} & \multicolumn{2}{|c|}{$\begin{array}{l}\text { No } \\
(n=41)\end{array}$} & \multirow[b]{2}{*}{$\begin{array}{l}t \\
(198)\end{array}$} & \multirow[b]{2}{*}{$p$} & \multicolumn{2}{|c|}{$95 \%$ CI } & \multirow[b]{2}{*}{ Cohen's d } \\
\hline & Mean & $S D$ & Mean & $S D$ & & & $L L$ & $U L$ & \\
\hline SWB & 161.55 & 22.31 & 151.41 & 17.71 & 2.69 & .000 & 2.71 & 17.54 & 0.50 \\
\hline QOL & 111.21 & 16.68 & 110.98 & 8.43 & 2.28 & .015 & -6.07 & 4.54 & 0.01 \\
\hline
\end{tabular}

SWB=Spiritual Wellbeing, $Q O L=$ Quality of Life

Application of independent sample t-test on insight about the disease shows that it is significant to spiritual wellbeing and quality of life. QOL and SWB have a positive relation with insight about the disease. That is when people know that they have some disease their spiritual wellbeing and Quality of life is get affected.

Table 13 Mean, Standard Deviations and $t$ for type of disease $(N=200)$

\begin{tabular}{|c|c|c|c|c|c|c|c|c|c|}
\hline \multirow[b]{2}{*}{ Variables } & \multicolumn{2}{|c|}{$\begin{array}{l}\text { Lung cancer } \\
(n=13)\end{array}$} & \multicolumn{2}{|c|}{$\begin{array}{l}\text { Blood cancer } \\
(n=19)\end{array}$} & \multirow[b]{2}{*}{$\begin{array}{l}t \\
(198)\end{array}$} & \multirow[b]{2}{*}{$p$} & \multicolumn{2}{|c|}{$95 \%$ CI } & \multirow[b]{2}{*}{ Cohen's d } \\
\hline & Mean & $S D$ & Mean & $S D$ & & & $L L$ & $U L$ & \\
\hline QOL & 112.62 & 5.93 & 109.79 & 14.05 & .682 & .000 & -5.64 & 11.29 & .26 \\
\hline SWB & 149.08 & 17.16 & 167.37 & 22.54 & 2.47 & .225 & -33.50 & -3.17 & -0.91 \\
\hline
\end{tabular}

SWB =Spiritual Wellbeing, $Q O L=$ Quality of Life

The above table shows that quality of life is significant to type of disease. High mean scores at lung cancer shows that individuals with lung cancer will have better quality of life than individuals' with blood cancer. It is found that spiritual wellbeing is non-significant to type of disease. Negative value of Cohen's d shows that sample did not responded accurately and carefully. 
Table 14 Mean, Standard Deviations and tor type of disease $(N=200)$

\begin{tabular}{|c|c|c|c|c|c|c|c|c|c|}
\hline \multirow[b]{2}{*}{ Variables } & \multicolumn{2}{|c|}{$\begin{array}{l}\text { Lung cancer } \\
(n=13)\end{array}$} & \multicolumn{2}{|l|}{$\begin{array}{l}\text { HIV++ } \\
(n=9)\end{array}$} & \multirow[b]{2}{*}{$\begin{array}{l}t \\
(198)\end{array}$} & \multirow[b]{2}{*}{$p$} & \multicolumn{2}{|l|}{$95 \%$ CI } & \multirow[b]{2}{*}{$\begin{array}{l}\text { Cohen's } \\
d\end{array}$} \\
\hline & Mean & $S D$ & Mean & $S D$ & & & $L L$ & $U L$ & \\
\hline SWB & 149.08 & 17.16 & 169.78 & 29.44 & 2.08 & .026 & -41.39 & -.006 & 0.85 \\
\hline QOL & 112.62 & 5.93 & 99.78 & 4.84 & 5.35 & .821 & 7.84 & 17.83 & 2.37 \\
\hline
\end{tabular}

SWB=Spiritual Wellbeing, $Q O L=$ Quality of Life

The table above shows that spiritual wellbeing is significant to type of disease in HIV++ and Lung cancer. Whereas quality of life is found to be non-significant. That is type of disease that is lung cancer and HIV++ has no effect on quality of life. A higher value of Cohen's d shows that there is strength of this relationship in sample.

Table 15 Mean, Standard Deviations and t for type of disease $(N=200)$

\begin{tabular}{|c|c|c|c|c|c|c|c|c|c|}
\hline \multirow[b]{2}{*}{ Variables } & \multicolumn{2}{|c|}{$\begin{array}{l}\text { Renal Failure } \\
(n=32)\end{array}$} & \multicolumn{2}{|c|}{$\begin{array}{l}\text { Asthma } \\
(n=21)\end{array}$} & \multirow[b]{2}{*}{$\begin{array}{l}t \\
(198)\end{array}$} & \multirow[b]{2}{*}{$p$} & \multicolumn{2}{|c|}{$95 \%$ CI } & \multirow[b]{2}{*}{$\begin{array}{l}\text { Cohen's } \\
d\end{array}$} \\
\hline & Mean & $S D$ & Mean & $S D$ & & & $L L$ & $U L$ & \\
\hline QOL & 109.79 & 14.05 & 111.10 & 24.04 & .214 & .000 & -8.35 & 10.35 & 0.06 \\
\hline SWB & 174.00 & 18.29 & 170.10 & 22.53 & .693 & .180 & -7.40 & 15.21 & 0.19 \\
\hline
\end{tabular}

SWB=Spiritual Wellbeing, $Q O L=$ Quality of Life

Quality of life is significant to type of disease. Mean scores shows that quality of life will be higher among individual with Asthma than renal failure. Spiritual well-being is non-significant to type of disease. That is spiritual wellbeing is not being affected by any type of disease. Positive value of Cohen's d shows that the respondents responded carefully.

\section{DISCUSSION}

The current study was conducted to find the relationship of spiritual wellbeing and Quality of Life among chronically ill individuals in Pakistani culture. It was also to see the effect of demographic variables on spiritual wellbeing and Quality of Life. For this purpose two scales were used that is Spiritual Wellness Inventory and WHO Quality of Life Questionnaire (WHOQOL-BREF). Spiritual well-being is often seen as a sense of connectedness to something larger than oneself, bringing with it a sense of meaning, purpose and personal value (Fisher, 2005).

Diagnosed Chronically ill individuals were taken from different hospitals. It was kept in view that only chronically ill patients will participate in research. Sample was clearly separated from 
individuals with acute illness. Acute illness refers to the condition of sickness starting from days and lasting for weeks (Morrison, 1998). Chronic illness refers to the condition in which patient suffers illness for longer period of time, usually above three months (Paterson, 2009).

\section{CONCLUSION}

Findings of the study demonstrate that spiritual wellbeing and Quality of life are positively related. Males were found spiritually high than females. Individuals with primary education scored higher on spiritual wellbeing than Middle, Matric, intermediate, bachelors, and masters. Adding to this, quality of life was high among patients with higher education and vice versa. Quality of life was found higher among married individuals than others whereas spiritual wellbeing was found higher among unmarried individuals. People belonging to middle socio economic status scored higher on quality of life than high and low SES. Quality of life is found higher among individuals with high monthly income. Whereas, spiritual wellbeing is found higher among patients with moderate monthly income than others. It is found significantly higher in middle adolescent than in late adolescent. It was also found that spiritual wellbeing is significantly higher among patients who have developed their insight about the disease. People having lung cancer have better quality of life than blood cancer patients. But spiritually well people with blood cancer are more recovered than lung cancer patients. Patients with HIV++ were more spiritually well than lung cancer patients, and quality of life of lung cancer patients were better than HIV++ patients. It was found that patients with Asthma were having better quality of life than renal failure patients, renal failure patients are more spiritually well than Asthma patients.

\section{REFERENCES}

Ali, M., David, J. H., Robert, M., James, M., \&Charles, R. G. (2003).Quality of life in lung cancer patients: does socioeconomic status matter? Health and Quality of Life Outcomes, 1,25- 45.Retrieved from doi: 10.1186/1477-7525-1-19

Azeemi, K.S. (2005). The Art and Science of Sufi Meditation. Houston: Plato Press.

Batool, N.(2010). Lack of spiritual wellness and Quality of Life as predictors of delinquent tendencies among adolescents.M.Sc dissertation.Unpublished.National Institute of Psychology, Quaid-e-Azam University, Islamabad.

Cantrell, Mary, A. (2000). Enhancing Hope among Early Female Survivors of Childhood Cancer via the Internet: A Feasibility Study. International Journal of Cancer Nursing, 31 (5), 370-379. Retrieved from doi: 10.1097/01.NCC.0000305766.42475.33

Chandler, A.(2000). The spirituality and therapy. United States: English Press. 
Cook, S. (2000). College students' perceptions of spiritual people and religious people. Journal of Psychology \& Theology, 28, 125-137.

David, M, O. (2009). Aging and spirituality: spiritual dimensions of aging theory, research and application. Binghamton: Haworth Press.

Denton \&Mitroff, (1999).Spirituality in the Workplace - A Measure of Success. The Journal of Behavioral and Applied Management, 3(3), 191

Dunn, H. L., Charles B. (1977). High-Level Wellness.Thorofare, NewYork: Inc.

Elizabeth. L. (1999).The Year of spirituality. New Heaven: MQ Publications.

Ferrans, C. (1996). Development of a conceptual model of quality of life. Scholarly inquiry for nursing practice: An International Journal, 10. (3), 293-304.

Fisher, J.W. (2005) Environment impacts on spiritual well-being in education. Journal of Religious Education, 57(1), 25-37.

Gohar, M. (2005).Development of an indigenous Spiritual wellness inventory for Pakistani youth.M- phill dissertation. Unpublished.National Institute of Psychology, Quaid-eAzam University, Islamabad.

Hall, A.B. (1992). Overcoming stigmatization: Social and personal implications of the human immunodeficiency virus diagnosis. Journal of Psychiatry Nursing, 6(3), 189-194.

Hanif, R., \&Gohar, M. (2010).Development of spiritual wellness scale (SWS- Urdu) for Pakistani Youth; in Akbar Husssain (2010).Exploration in Human Spirituality: New Delhi: Global Vision Publishing House.

Heintzman, P. (2002). A conceptual model of leisure and spiritual well-being.Journal of Park and Recreation Administration, 20(4), 147-169.

Hill, P. C., Pargament, K. I., Hood, R. W. Jr., McCullough, M. E., Swyers, J. P., Larson, D. B., \&Zinnbauer, B. J. (2000). Conceptualizing religion and spirituality: Points of commonality, points of departure. Journal for the Theory of Social Behavior, 30, 51-77.

Ingersoll, R E (1998). Redefining dimensions of spiritual wellness: a cross traditional research. Unpublished

Jackson, R., Monteux, A. (2003). Promoting the Spiritual Wellbeing of Children and Young People with Special Needs.Scottish. Journal of Residential Care, 2(1), 56-76. 
James, Smith. Mark.,Kamy., Matt., Will., Bauch. (2001). Social and Health Services.Journal of Advance Nursing, 9(3), 297-301.

Jenkins, J. (2000). Spirituality and meaning in supportive care: spirituality- and meaningcentered group psychotherapy interventions in advanced cancer. Supportive Care in Cancer, 10(4), 272-280. Retrieved From DOI: 10.1007/s005200100289

Kevin, S. (2000). Spiritual and religious experience. Counseling and Values, 42, 128-132.

Lancet, A. (2003).Health and Quality of Life Outcomes.InternationalJournal of Science, 3(10), 189-192. Retrieved from doi: 10.1186/1477-7525-3-10

Larson,Swyers\& McCullough. (2000). Spirituality and Health: Is There a Relationship? Journal of Health Psychology, 4(3), 291-300.

Legere, T. E. (1984). Spirituality for today. Studies in Formative Spirituality, 5, 375-383.

Mark., Otis., Angela., Yzette., Crystal., \&Shawn. (2009). The A to Z of African-American Television. Melbourne: Melbourne Press Club.

Matt, K. (2001).Spirituality, Breast Cancer Beliefs and Mammography Utilization among Urban African American Women.Journal of Health Psychology, 8(3), 383-396

Miller, R. (1997). Spirituality, religion, and health: An emerging research field. Journal of Religion and Health, 58(1), 24-35.

Power, M., Bullinger, M., \& Harper, A. (2003). The World Health Organization WHOQOL-100: Tests of the universality of quality of life in 15 different cultural groups worldwide. Health Psychology, 18(5), 495.

Paterson, M. (2009). The art of occupational therapy: in relation to chronic illness. Journal of Applied Research in Intellectual Disabilities, 13(4), 255-275.

Reed, Linda. L.,\& Dunn. (2009). Existential well-being predicts perceived control in adults with heart failure. Applied Nursing Research, 22, (3), 198-203

Robert,G. (2010). Effects of Estrogen plus Progestin on Health-Related Quality of Life.The New England Journal of Medicine, 348(6), 99- 119.

WHO-QOL Group. (1995).The World Health Organization.QOL Assessment position paper from the World Health Organization, Social Sciences and Medicine, 14, 1403-1409.

WHO-QOL Group. (2005).The World Health Organization-QOL Assessment position paper from the World Health Organization. Social Sciences and Medicine, 14(1), 149-161. 